\title{
Tube Suction Test to Measure Moisture Susceptibility of Australian Pavements
}

\author{
Yang Sheng Yeo ${ }^{\mathrm{a}, *}$, Hamid Nikraz $^{\mathrm{b}}$, and Peerapong Jitsangiam ${ }^{\mathrm{c}}$ \\ Department of Civil Engineering, Curtin Engineering Faculty, GPO Box U1987, Perth, Western Australia \\ 6845, Australia \\ E-mail: byeo@globalskm.coma,*,h.nikraz@curtin.edu.aub,p.jitsangiam@curtin.edu.auc
}

\begin{abstract}
Moisture ingress is a primary catalyst for pavement damage and plays a key role in the performance of pavement materials in service. Moisture intrusion eventuates to early development of deficiencies (potholes) due to "pumping" effects and reduced effective strength of the pavement. Cement stabilisation is one of the preventive measures that are applied to minimise moisture ingress into pavements. This study utilises the Tube Suction Test (TST), developed by Texas Department of Transportation (TxDOT), to assess its robustness as an engineering tool to measure moisture ingress and to determine the relationship between water ingress and cement content. The TST is a non-destructive testing method that measures the dielectric value (DV) of materials which is a measure of the moisture content. Mixes ranging from $1 \%$ to $6 \%$ cement content by mass are tested. The results allow the determination of a DV tangent which potentially characterises the moisture susceptibility of stabilised material. Results also show that a marked improvement in moisture susceptibility is achieved with 3\% cement content. Preliminary results obtained from this study shows that TST may have the potential for industrial application but will require further investigations.
\end{abstract}

Keywords: Tube suction test, moisture, pavements, stabilization.

ENGINEERING JOURNAL Volume 16 Issue 4

Received 8 January 2012

Accepted 4 June 2012

Published 1 July 2012

Online at http://www.engj.org/

DOI:10.4186/ej.2012.16.4.159 


\section{Introduction}

Despite the importance of water during construction to achieve compaction, its detrimental effects on pavements cannot be dismissed especially since road embankments are so often exposed to harsh weather scenarios and are critical in maintaining access during and such severe climatic events. However, imperfections in compaction, inconsistent material gradation, construction defects, and other factors, leads to increased vulnerability of pavements to moisture induced damage.

Moisture enters pavements through various mechanisms which include infiltration, seepage, capillary and fluctuations in water table as shown in Fig. 1 [1] below. These mechanisms are highly dependent on the permeability of pavement materials and its subgrades.

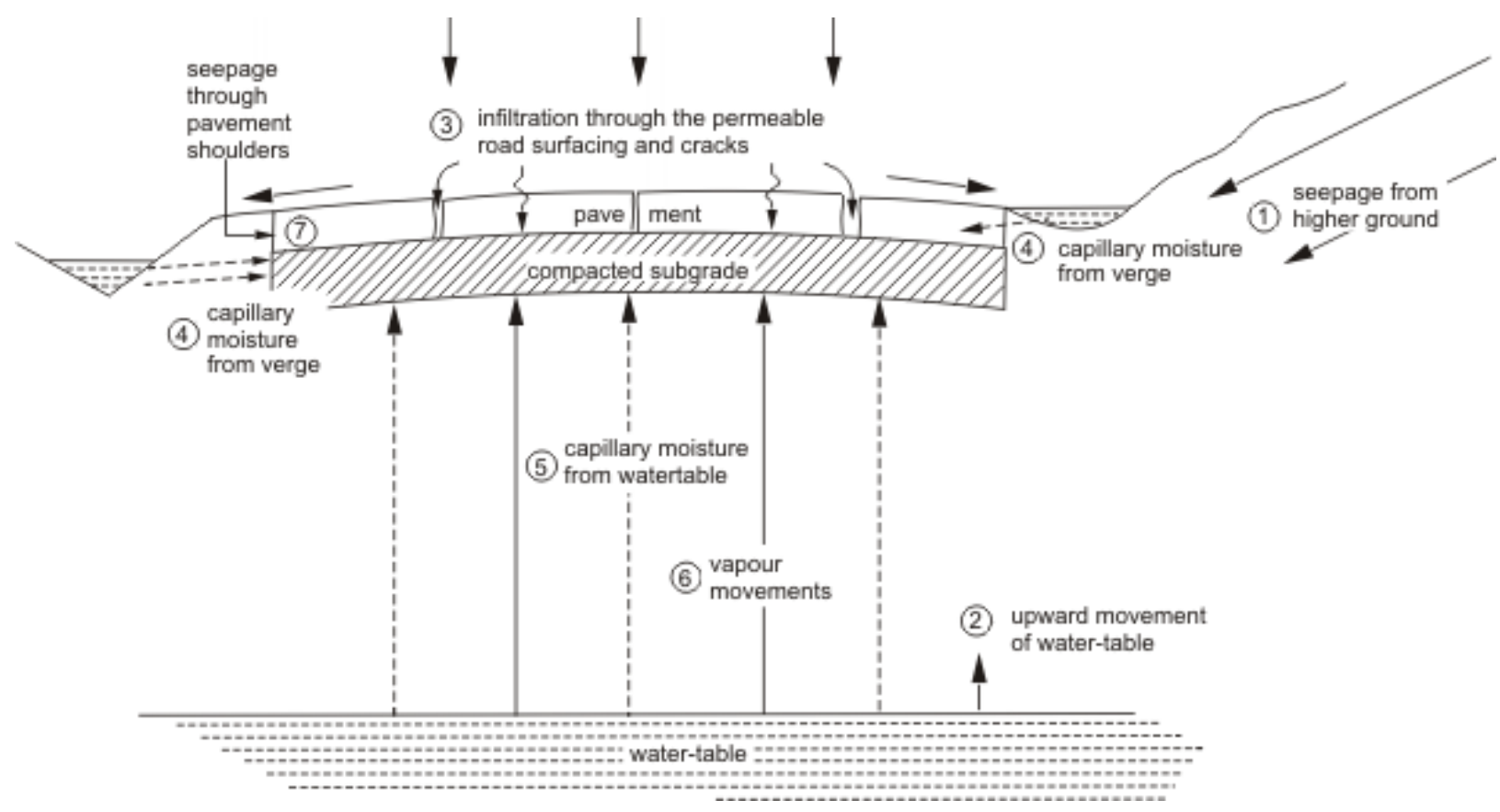

Fig.1. Mechanisms of moisture intrusion into pavement [1].

With the combined effects of moisture ingress and traffic loading, voids are formed at the interface of pavement layers or at the subgrade. This induces a pumping effect or reduced subgrade support which eventuates to water induced damage such as potholes and alligator cracking as shown in Fig. 2 below.

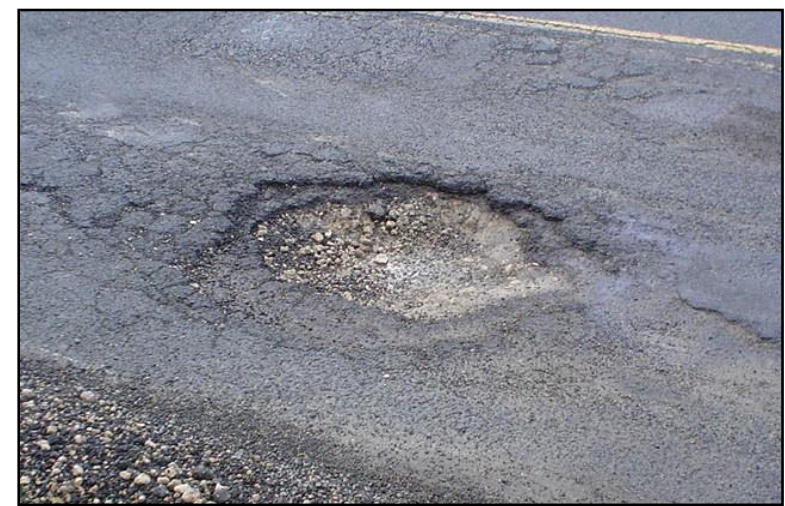

(a)

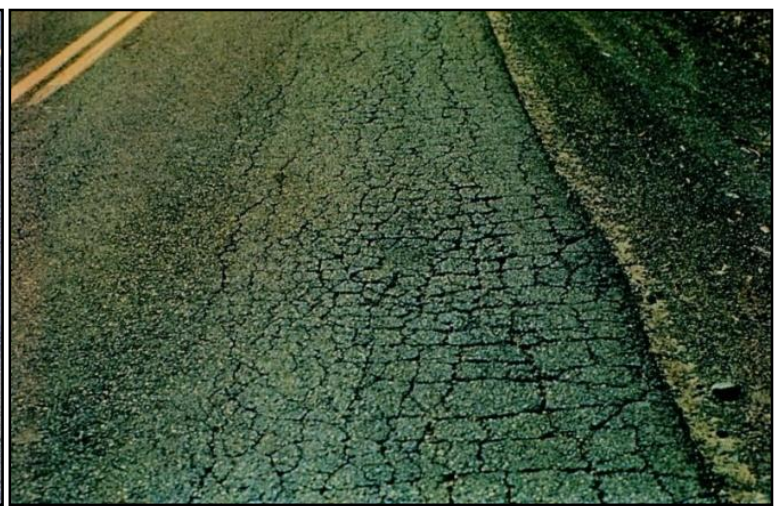

(b)

Fig. 2. Deteriorated pavements due to Water induced damage, (a) pothole (b) alligator cracking [2].

With this risk of undergoing water induced damage, pavements are designed with two control measures, i.e. to either allow water to drain freely through the pavements or to minimise water ingress into 
the pavement structural layers. While subterranean drains and permeable sub-base layers are used typically to achieve the first of the two methods, cement stabilised layers are constructed to assist in minimising moisture fluctuations of pavements by forming a theoretically impermeable layer.

However, even when a cemented layer is used, the issue of moisture ingress is not eliminated. The durability of cement stabilised base courses are compromised when moisture is present in the pavement layer. The Texas Department of Transportation (TxDOT) has in the past experienced the "disappearing" of stabilisation content through the service life of a pavement [3]. It was concluded that the loss of stabilisation was due to moisture ingress which causes a chemical retardation [3]. This is consistent with 100 case studies in South Africa [4] and observations in trial pavements constructed in Western Australia. Main Roads Western Australia (MRWA) constructed several trial pavements in 1996 to observe the performance of cementitiously modified base course material, i.e. pavements with low stabilising content or disturbed prior to placement. Between the years 1996 to 2008, observations of these trial pavements noted that the stabilising agents within base courses have experienced a similar fate [5]. It was discussed within Harris and Lockwood's report that this deterioration was associated to the chemical retardation process known as carbonation, a process that occurs with the presence of water.

Carbonation occurs in cemented pavement layers because the calcium bearing phases present are attacked by carbon dioxide of the air and converted to calcium carbonate based on the following process [4].

$$
\mathrm{Ca}(\mathrm{OH})_{2}+\mathrm{CO}_{2} \rightarrow \mathrm{CaCO}_{3}+\mathrm{H}_{2} \mathrm{O}
$$

Essentially, this means that a reversal of reaction occurs and the stabilising agents revert to its original components and are now more easily dissolved into water.

Furthermore, an inadequately compacted cement stabilised base course has also the propensity to allow water to be trapped at the interface between layers [6]. When loaded, a surge in pore pressure will also cause the "pumping" effect that will severely damage pavements.

\section{Scope of Research}

Given the crucial role water plays in the detriment of stabilised pavements, this paper investigates two main topics:

- the applicability of TST as an engineering tool to assess moisture susceptibility;

- the relationship between cement content and pavement's susceptibility to moisture ingress.

\section{Tube Suction Test, Dielectric Measurement and Its Relationship to Strength T}

The Tube Suction test is a novel testing methodology to ascertain susceptibility of pavement materials to moisture intrusion. The earlier form of Tube Suction Test was developed by the Texas Department of Transport ((TxDOT) to analyse the behaviour of ground-penetrating radar (GPR) signals of pavement materials [7] to formulate non-destructive methods for assessing in service roads.

From these tests, it was noted that the dielectric constant value, DV, of materials was capable of characterising pavement materials, in particular its relationship to moisture content. Through further funded research and a joint investigation between the Finnish National Road Administration and the Texas Transportation Institute (TTI), a standard Tube Suction Test was developed to assess the moisture susceptibility of granular materials [8]. Further researches were then undertaken by [3], [9] and [10] on the moisture susceptibility of cement stabilised materials using the Tube Suction Test with promising results to ascertain the durability of the material.

The Tube Suction Test basically uses a percometer as shown in Fig. 3 below, to measure the DV of a material. The 'percometer' is derived from the words permittivity (per-), conductivity (-co-) and meter. It is a frequency domain instrument commonly used to measure soil dielectric permittivity and conductivity in agricultural studies [11]. The percometer is equipped with a specially designed metal probe which acts as an electrical capacitor that measures the electrical capacitance of its surrounding media by means of dielectric permittivity. 


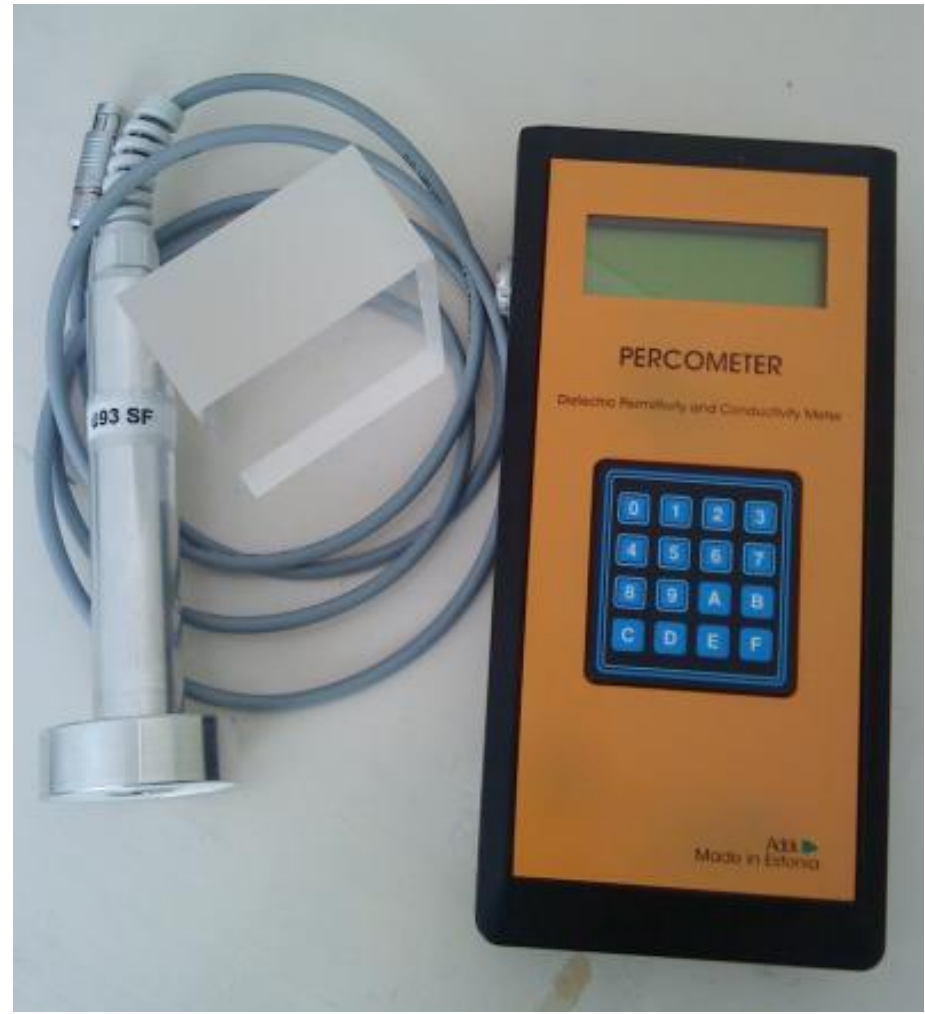

Fig. 3. Percometer with Surface Probe.

Dielectric permittivity is a complex function consisting of real and imaginary components. The imaginary part of dielectric permittivity is expressed as dielectric loss which indicates attenuation and dispersion. Meanwhile, the real part of dielectric permittivity is expressed as dielectric value, DV, which is the parameter of interest for this study. DV is essentially the ratio of electrical energy stored in a material by an applied voltage to the energy stored in a vacuum. In typical conditions, DV of air is 1.0 while water is 80. Hence, given that a dry pavement material typically ranges from DV measurements of 2 to 5 , the presence of water will fill the voids within the pavement materials subsequently affecting its DV. It is for this reason that a distinct relationship exists between dielectric value and water content [12].

When the percometer's probe is placed on a pavement surface (lab specimen or in situ), the measurement provides an indication of the volumetric water content of the pavement material in the form of DV. By plotting the dielectric value over time, the moisture sensitivity of a material can be assessed by observing the DV value attained and the shape of the graph [12]. A similar dependence between dielectric value and moisture in concrete also exists [13].

\section{Specimen Preparation and Testing Regime}

The aggregates used for the test are crushed rocks sourced from a quarry in Western Australia which meets Main Roads Western Australia Specifications 501 [14]. These crushed rocks are used widely in Western Australia for road basecourse construction. General Purpose (GP) cement is used as the stabilisation agent. The stabilisation content studied ranges from $1 \%$ to $6 \%$ cement content by mass.

Sample preparation method was primarily based on Australian Standard AS5101.4 [15]. The cement was first dry mixed with the aggregates before adding water to reach the OMC of the mix. Three specimens for each cement content mix were prepared by compacting the treated materials into $105 \mathrm{~mm}$ (diameter) $\mathrm{x}$ $115 \mathrm{~mm}$ (height) steel moulds by applying the modified compaction method. Specimens are compacted to a target modified dry density $2.35 \mathrm{t} / \mathrm{m}^{3}$. The summary of OMC of each mixes is presented in Table 1 below. 
Table 1. OMC for various cement content of stabilised basecourse.

\begin{tabular}{lllllll}
\hline Cement Content & $1 \%$ & $2 \%$ & $3 \%$ & $4 \%$ & $5 \%$ & $6 \%$ \\
\hline OMC (\%) & 5.75 & 6.00 & 6.25 & 6.50 & 6.75 & 7.00 \\
\hline
\end{tabular}

The specimens were then cured for 7 days in a fog chamber available at the laboratory of Curtin University which was maintained at a constant temperature and relative humidity to control the test parameters. The relative humidity of the fog chamber was measured to be $70 \%$ promoting the curing process. After the 7 days of curing, the specimens were allowed to dryback for 24 hours in an oven at $60^{\circ} \mathrm{C}$ to remove all moisture content as practiced by other preceding authors detailed in the background. Specimens were then wrapped with a plastic liner before being soaked in an enclosed water bath for 9 days. The test setup is shown in Fig. 4 below.

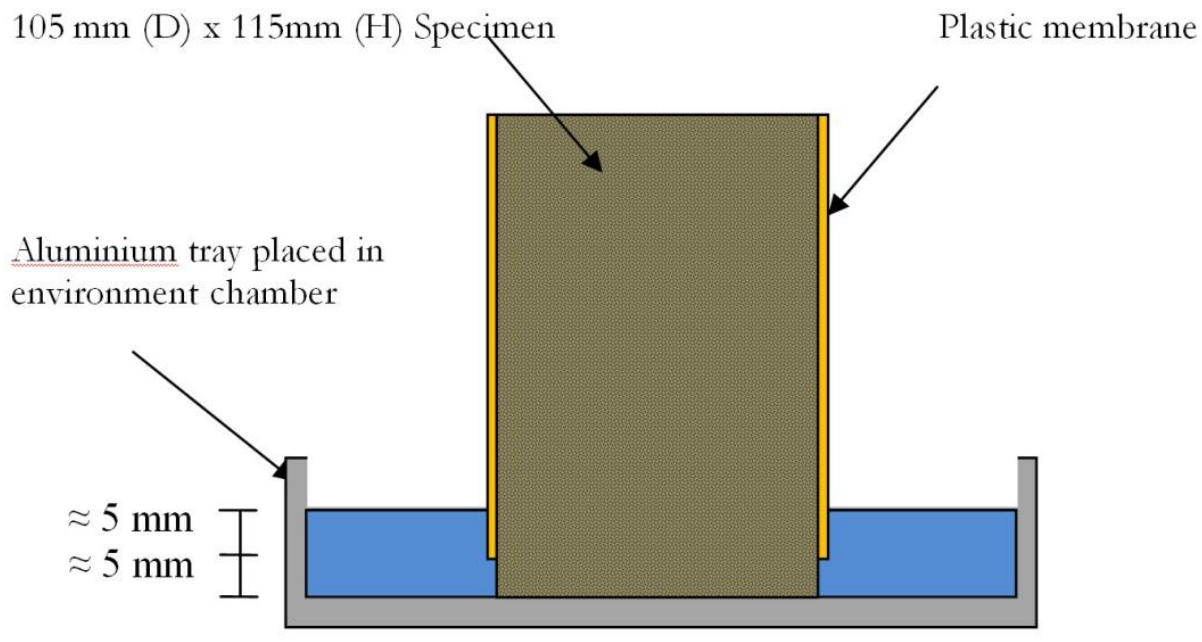

Fig. 4. TST test setup.

Dielectric values are then measured using the percometer every 24 hours at 5 different locations on the surface and the specimen weighed in line with the proposed methodology developed by [8]. Fig. 5 below shows the DV measurement being undertaken.

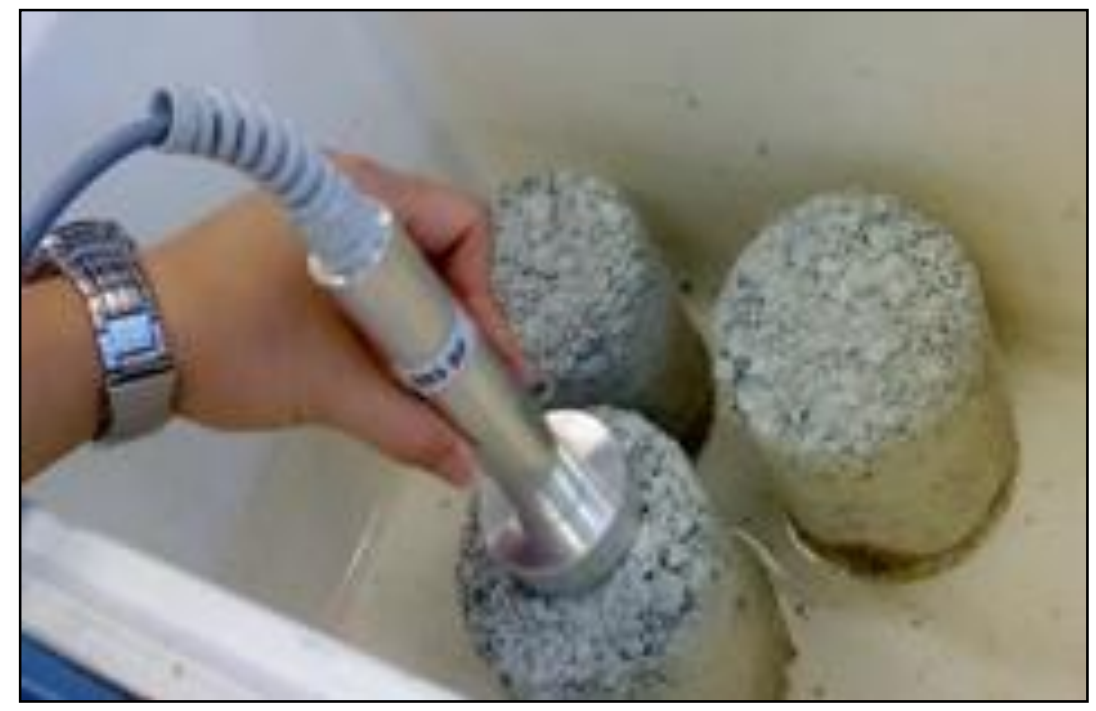

Fig. 5. Measurement of Dielectric Value, DV. 


\section{Tube Suction Test Results and DV Tangent}

The DV of specimens plotted against time over the course of the experiment is shown in Figs. 6(a) to (e).

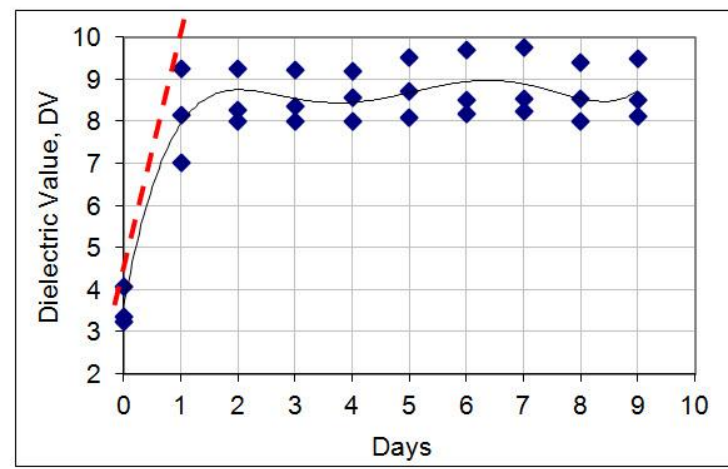

(a)

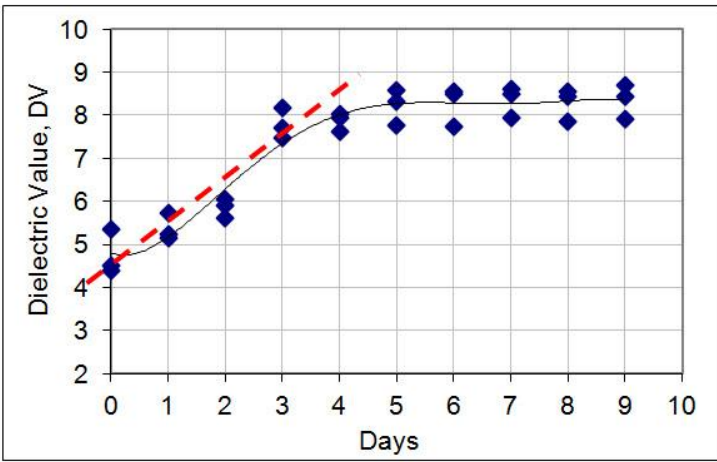

(c)

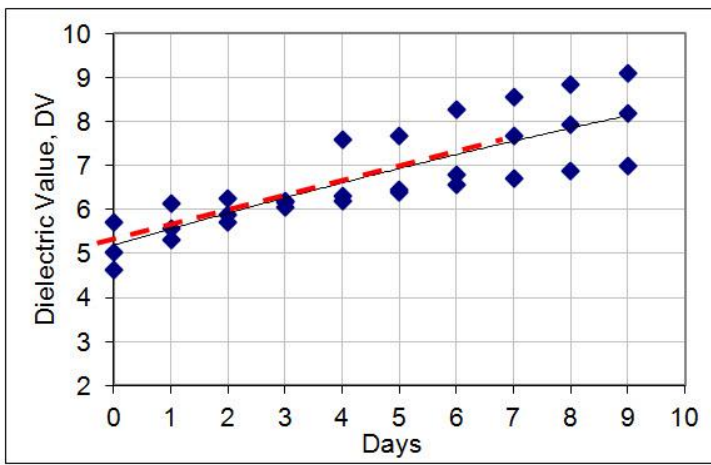

(e)

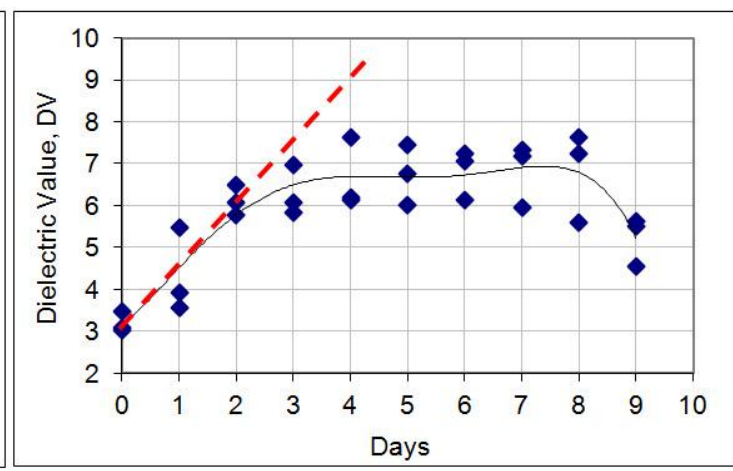

(b)

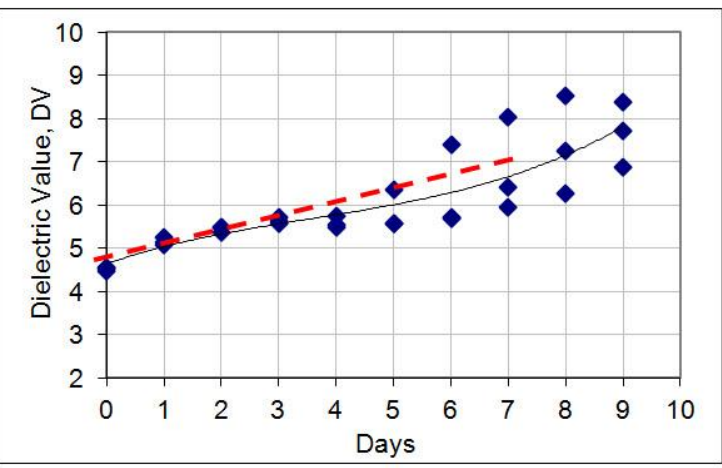

(d)

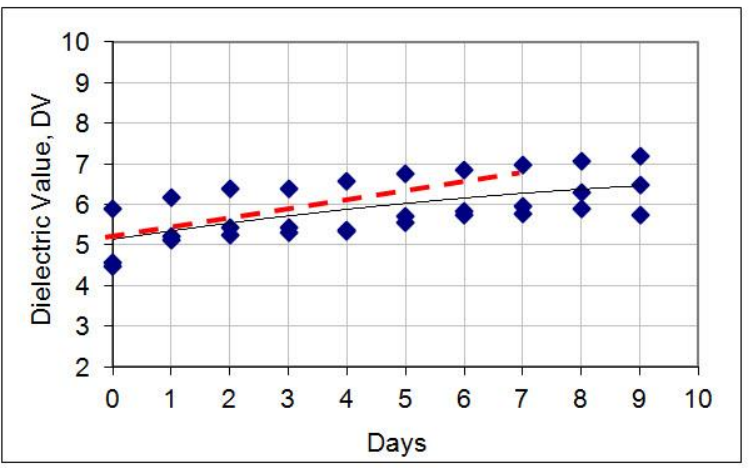

(f)

Fig. 6. Dielectric value over testing period for (a) 1\% Cement; (b) 2\% Cement; (c) 3\% Cement; (d) 4\% Cement; (e) 5\% Cement; (f) $6 \%$ Cement.

The DV of each mix design at the start of each test, i.e. after 24 hour dry back, generally rose when cement content increase. It ranges from approximately DV $=3$ at $2 \%$ cement to DV $=5$ at $6 \%$ cement. Within the tested timeframe, the $2 \%$ and $3 \%$ cement mix saw the specimens reaching a distinct saturation point while specimens with $4 \%$ cement content and above did not. It is also noted that specimens at $2 \%$ cement mix experienced a plunge on the final reading which can be associated to specimen mishandling. The profile of TST results test has also been discussed in [12], where the plateau profiles shown for 
specimens $2 \%$ and $3 \%$ are typically noted as lower performing material compared to the constant profiles shown by the other specimens.

However, a more distinct trait noted from the Tube Suction Test was the initial rate of increase of DV measured from the tangent of the fitted curve (shown as a red dotted line on Figs. 6 (a) to (f)), denoted as the DV tangent. The DV tangent generally represents the rate of moisture ingress and which can characterise the moisture susceptibility of stabilised specimens and subsequently the durability of the specimen. The analysis shows that the DV tangent reduces when cement content increases and a specific leap from 3\% to $4 \%$ cement content can be observed. This indicates that moisture susceptibility of cement stabilised materials reduces with increasing cement content. By $4 \%$ cement content the moisture susceptibility reduces significantly which implies that a higher resistance to moisture ingress. The DV tangent is summarised in Table 2 below.

Table 2. DV Tangent from tube suction test.

\begin{tabular}{lcccccc}
\hline Cement Content (\%) & 1 & 2 & 3 & 4 & 5 & 6 \\
\hline DV Tangent (DV/day) & 4.59 & 1.40 & 0.92 & 0.31 & 0.35 & 0.17 \\
\hline
\end{tabular}

By plotting the above data as shown in Fig. 7 below, it is noted that a power relationship exists between DV tangent and cement content. At $1 \%$ cement content, the propensity for moisture ingress is relatively high and decreases significantly at $2 \%$ cement content, tapering off to a steady dielectric tangent at $4 \%$ cement content.

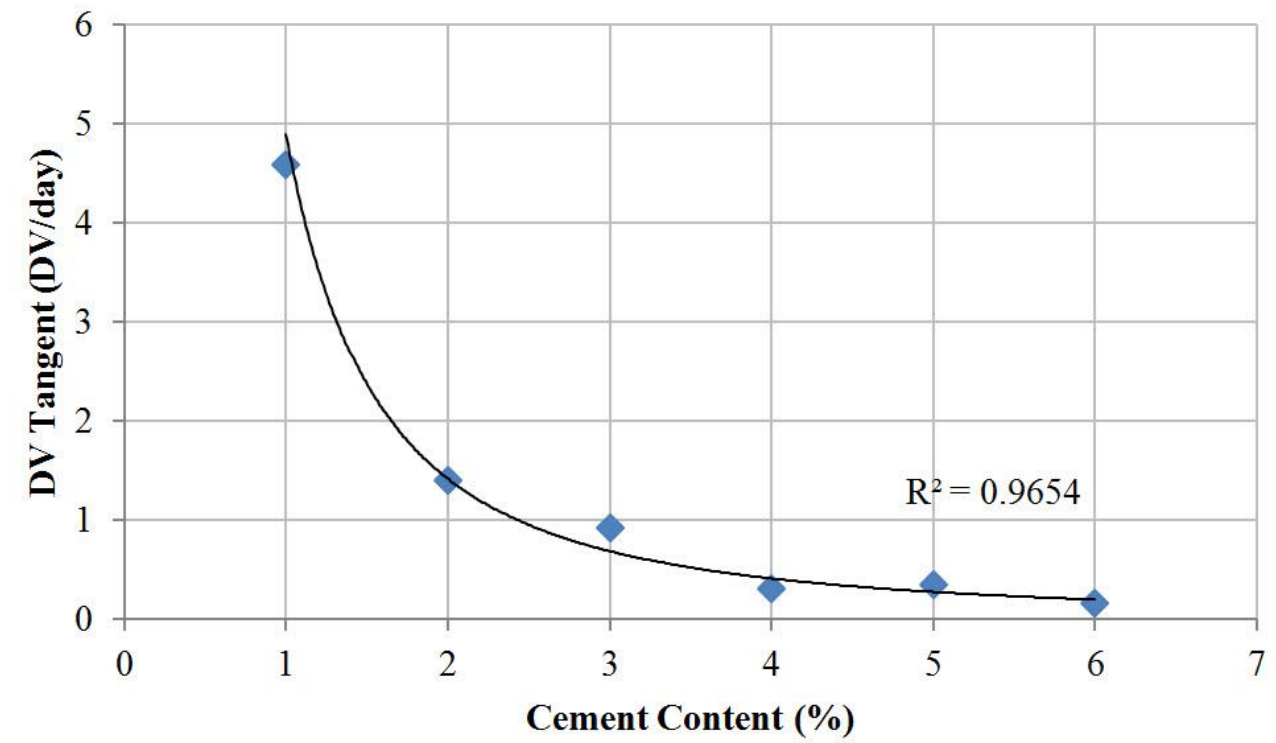

Fig. 7. DV Tangent vs. Cement Content.

The test results have demonstrated that a trend exists between the rate of increase of dielectric value and cement content, denoted as the DV tangent, and is defined by a power function. This provides an indication of the susceptibility of the stabilised basecourse to water ingress. Based on the test results, the DV tangent measured in this test provides a relative indication of the moisture susceptibility of specimens. In general, lower measurements of maximum DV and DV tangent indicates a lower susceptibility to moisture ingress and thus a more durable cement stabilised pavement mix design. From the tests undertaken, at 3\% cement content by mass, the base course specimen exhibits marked improvement against moisture sensitivity. 


\section{Implications of Tube Suction Test}

The study has also demonstrated that the Tube Suction Test (TST) is a viable tool for the industry to assess the behaviour of cement treated basecourse with regards to its performance in moisture susceptibility. The procedure involves a simple two step approach of first drying a cement treated pavement material specimen followed by a soaking period where DV is measured. It also involves standard specimen sizes used typically for geotechnical testing works, which means specimens can be recycled to undertake other testing upon completion. UCS tests have been undertaken by other authors as noted in the background of this study. In a nutshell, this is a highly favourable tool as the plant and labour required for the test is relatively cost effective.

However, a critical component of the TST is to assess the accuracy of the measurement. Since specimens were weighed every time DV measurements were performed, the water content of the specimens could be compared against DV. This is shown in Fig. 8 below.

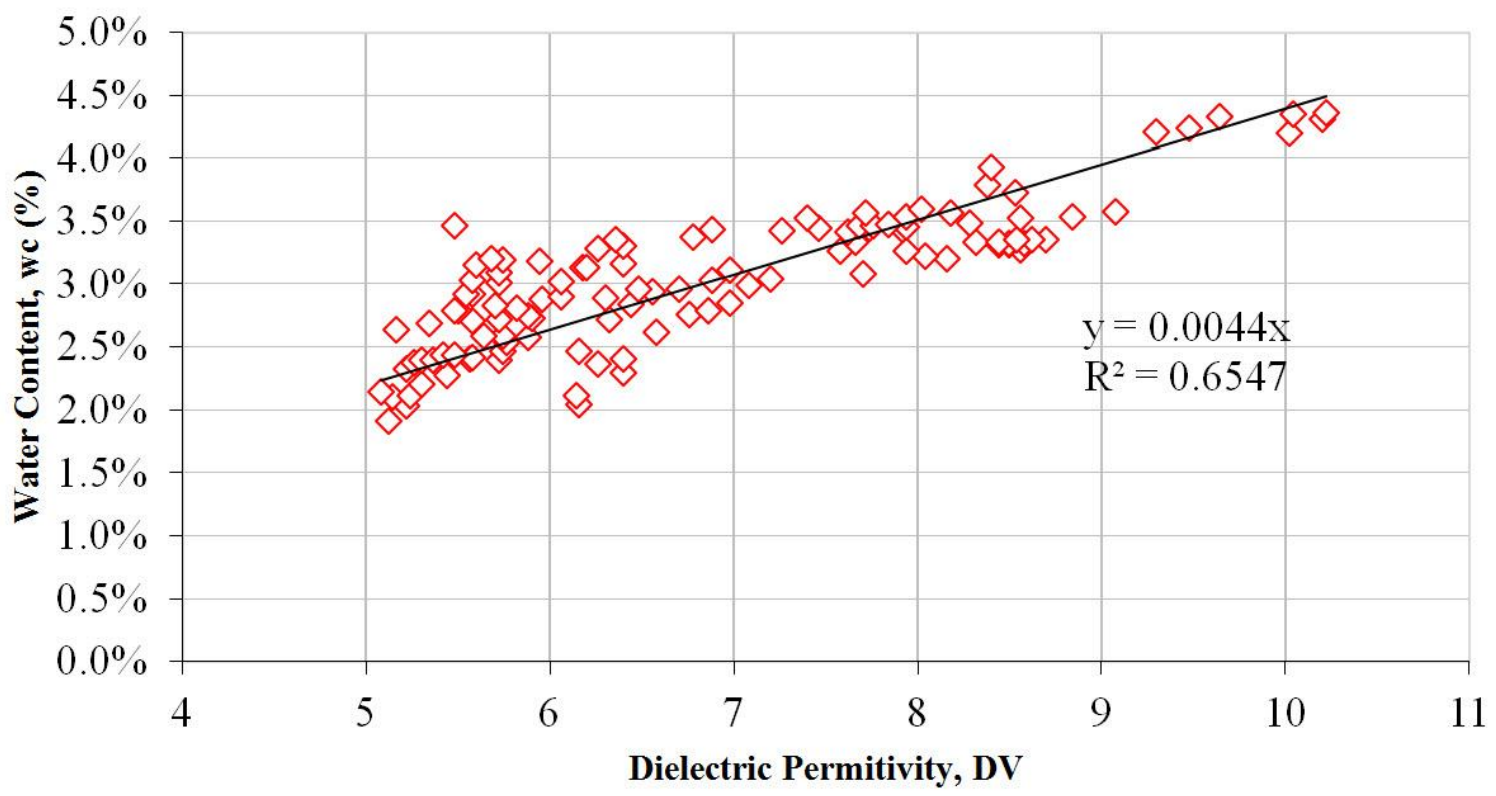

Fig. 8. Dielectric value, DV vs. water content, wc (\%).

The results above shows the TST provides a reading of moisture content within a $\pm 0.5 \%$ error margin. This level of reliability of percometers to measure water content potentially mean that once the percometer is calibrated, it may potentially be used as a non-destructive measurement device to assess water content of in situ pavements. Subsequently, the TST may also be used as a tool to characterise moisture susceptibility of stabilised pavement materials in Western Australia for design purposes. Nevertheless, it is recognised that there are several considerations that requires further investigation in order to provide more confidence to potential TST users, especially with regards to establishing industry practices for specimen preparation and curing.

It is recommended that more laboratory tests are undertaken followed by in-situ tests using other materials. This will provide better assurance for the TST to characterise unbound granular material as practiced in other parts of the world.

\section{Acknowledgement}

The author would like to thank Tom Scullion from TTI for his technical advice and Hock Hing Chua and Mark Whittaker for laboratory assistance. 


\section{References}

[1] M. G. Lay, Handbook of Road Technology: Planning and Pavements, vol. 1, 3rd ed. Amsterdam, the Netherlands: Gordon and Breach Science Publishers, 1998.

[2] Pavementinteractive. [Image]. Available: http://www.pavementinteractive.org

[3] T. Scullion, S. Sebesta, J. P. Harris, and I. Syed, "Evaluating the performance of soil-cement and cement-modified soil for pavements: a laboratory investigation," Portland Cement Association, Illinois, RD120, 2005.

[4] P. Paige-Green, F. Netterberg, and L. R. Sampson, "The carbonation of chemically stabilised road construction materials: guide to identification and treatment," Division of Road and Transport Technology, CSIR, Pretoria, 1990.

[5] D. Harris and N. Lockwood, "Reid highway basecourse test sections performance to December 2008: Revision of report no. 2004/17M," Main Roads Western Australia, Western Australia, Pavements Engineering Report no. 2009/5M, vol. 1, 2009.

[6] N. Thom, Principles of pavement engineering. London: Thomas Telford Publication, 2008.

[7] W. S. Guthrie and T. Scullion, "Interlaboratory study of the tube suction test," Texas Transportation Institute, Texas, Report No. 0-4114, 2003.

[8] B. G. Barbu and T. Scullion, "Repeatability and reproducibility study for tube suction test," Texas Transportation Institute, Report No. 5-4114-01-1, Texas, 2005.

[9] W. S. Guthrie, S. Sebesta, and T. Scullion, "Selecting optimum cement contents for stabilizing aggregate base materials," Texas Transportation Institute, Texas, Report No. 7-4920-2, 2001.

[10] K. P. George, "Feasibility of tube suction test as a substitute for durability tests," Portland Cement Association, Illinois, 2001.

[11] T. Saue, J. Kadaja, and T. Plakk, "Measurement of soil water content by percometer," in Workshop Program and Papers: 1st Global Workshop on High Resolution Digital Soil Sensing and Mapping, Sydney, 2008, pp. 184-192.

[12] T. Saarenketo, "Tube suction test-results of round robin tests on unbound aggregates," Finnish National Road Administration, Laplan, 2000.

[13] J. R. Bell, G. A. Leonards, and W. A. Doch, "Determination of moisture content of hardened concrete by its dielectric properties," in Proceedings to the American Society for Testing and Materials, New York, 1963.

[14] Main Roads Western Australia, "Specification 501: pavements," Perth, Document No. 04/10110-04, 2011.

[15] Methods for Preparation and Testing Stabilized Materials-Method 4: Unconfined Compressive Strength of Compacted Materials, Australian Standards, New South Wales, AS 5101.4-2008, 2008. 
